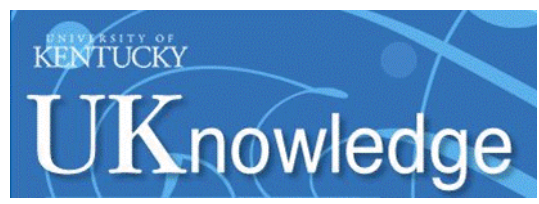

University of Kentucky

UKnowledge

\title{
Liver-FibroSTARD Checklist and Glossary: Tools for Standardized Design and Reporting of Diagnostic Accuracy Studies of Liver Fibrosis Tests
}

\author{
Jérôme Guéchot \\ Saint-Antoine Hospital, France \\ Jérôme Boursier \\ LUNAM University, France \\ Victor de Ledinghen \\ Université de Bordeaux, France \\ Thierry Poynard \\ University Pierre et Marie Curie, France
}

Fabrice Carrat

Sorbonne Universités, France

Follow this and additional works at: https://uknowledge.uky.edu/internalmedicine_facpub

see rext of the fordiciditional Healthors Sciences Commons

Right click to open a feedback form in a new tab to let us know how this document benefits you.

\section{Repository Citation}

Guéchot, Jérôme; Boursier, Jérôme; de Ledinghen, Victor; Poynard, Thierry; Carrat, Fabrice; Leroy, Vincent; Wong, Grace Lai-Hung; Friedrich-Rust, Mireen; Fraquelli, Mirella; Plebani, Mario; Sebastiani, Giada; Myers, Robert; Angulo, Paul; Bertrais, Sandrine; Wendum, Dominique; Bricault, Ivan; and Calès, Paul, "LiverFibroSTARD Checklist and Glossary: Tools for Standardized Design and Reporting of Diagnostic Accuracy Studies of Liver Fibrosis Tests" (2015). Internal Medicine Faculty Publications. 65.

https://uknowledge.uky.edu/internalmedicine_facpub/65

This Editorial is brought to you for free and open access by the Internal Medicine at UKnowledge. It has been accepted for inclusion in Internal Medicine Faculty Publications by an authorized administrator of UKnowledge. For more information, please contact UKnowledge@lsv.uky.edu. 


\title{
Liver-FibroSTARD Checklist and Glossary: Tools for Standardized Design and Reporting of Diagnostic Accuracy Studies of Liver Fibrosis Tests
}

\author{
Digital Object Identifier (DOI) \\ https://doi.org/10.1515/cclm-2015-0241 \\ Notes/Citation Information \\ Published in Clinical Chemistry and Laboratory Medicine, v. 53, no. 8, p. 1135-1137. \\ (c)2015 by De Gruyter.
}

The copyright holders have granted the permission for posting the article here.

Authors

Jérôme Guéchot, Jérôme Boursier, Victor de Ledinghen, Thierry Poynard, Fabrice Carrat, Vincent Leroy, Grace Lai-Hung Wong, Mireen Friedrich-Rust, Mirella Fraquelli, Mario Plebani, Giada Sebastiani, Robert Myers, Paul Angulo, Sandrine Bertrais, Dominique Wendum, Ivan Bricault, and Paul Calès 


\section{Editorial}

Jérôme Guéchot, Jérôme Boursier, Victor de Ledinghen, Thierry Poynard, Fabrice Carrat, Vincent Leroy, Grace Lai-Hung Wong, Mireen Friedrich-Rust, Mirella Fraquelli, Mario Plebani, Giada Sebastiani, Robert Myers, Paul Angulo, Sandrine Bertrais, Dominique Wendum, Ivan Bricault and Paul Calès, from the ARDENT group and/or AFEFa

\section{Liver-FibroSTARD checklist and glossary: tools for standardized design and reporting of diagnostic accuracy studies of liver fibrosis tests}

DOI $10.1515 / \mathrm{cclm}-2015-0241$

Chronic liver diseases are highly prevalent and require an accurate evaluation of liver fibrosis to determine patient management. Many efforts have been made over this last decade to develop accurate non-invasive tools for liver fibrosis evaluation as alternative methods to liver biopsy. These non-invasive methods of liver fibrosis assessment including blood markers and liver stiffness measurement by elastography are increasingly well validated and contribute to safer and more practical clinical care for patients $[1,2]$. These efforts have led to a dramatic increase in the number of diagnostic accuracy studies of liver fibrosis tests and to a proliferation of reports whose quality is very heterogeneous.

The validation of the diagnostic test is a critical issue for their widespread use in clinical practice [3]. The results of diagnostic accuracy studies are the basis to inform how to interpret test results and to consider the likelihood that errors occur in clinical decision. Guidelines aim to help for reporting the researches more completely to ensure that the papers are more useful and are not misleading [4]. The Standards for Reporting of Diagnostic Accuracy Studies (STARD), simultaneously published in 2003 in 13 biomedical journals, including Clinical Chemistry and Laboratory Medicine [5] were developed aiming to "improve the accuracy and completeness of reporting of studies of diagnostic accuracy, to allow readers to assess the potential for bias in the study (internal validity) and to evaluate its generalizability (external validity)". The STARD checklist, comprising 25 items summarizing the important information that has to be present in scientific reports, has been included in the instructions to authors of more than 200 scientific journals. Over the years, the reporting of many individual STARD items improved however, the STARD authors agreed that these statements should be updated [6] and the original checklist was supplemented with guidance pertinent to studies of specific disorders in human [7-9], veterinary medicine [10] or epidemiology [11].

For the diagnostic accuracy studies of non-invasive liver fibrosis tests, the STARD criteria represent an excellent base to start off. However, these studies have particular features that are not taken into account by the current STARD statements. While fibrosis staging is of high clinical significance in patients with chronic liver diseases, the difficulties due not only to the absence of an absolute gold standard (liver biopsy examination is a limited "gold" standard [12]), but also to the spectrum bias [13], and to the specificities for ordinal references such as pathological staging [14] made essential to develop specific validated standards of study design and reporting.

A group of eight experts of different specialties (hepatology, biology, radiology, pathology, and biostatistics) chosen by the board of the French Association for the Study of the Liver [Association Française pour l'Étude du Foie (AFEF)] evaluated STARD statements adequacy in 10 diagnostic studies about non-invasive liver fibrosis tests, and considered than more than a half of the 25 STARD items were only partially adequate for this purpose [15]. Therefore, they attempted to establish a consensus for quality standards by adapting the STARD criteria to the requirements of liver fibrosis testing and then developed an extended version developed specifically for those studies. The process resulted in introducing two new items and 42 sub-items within the 25 STARD items [16]. A comprehensive glossary including explanations and examples for each item/sub-item was also drafted and approved by the panel of experts [17].

The Liver-FibroSTARD checklist and glossary were independently submitted to seven international experts in order to test and validate the new standard statements. 
The independent evaluation showed at least very good inter-expert agreement for two thirds of the items/subitems [15]. After this second external evaluation, material was finally improved. The new Liver-FibroSTARD checklist [16] and glossary [17] are freely available at the URLs mentioned in these references.

An accelerated development of improved markers has been recommended in order to integrate non-invasive tests of liver fibrosis as endpoints into future clinical trial design of antifibrotic drug [18]. High-quality studies are required for validation of cut-offs to stage fibrosis according to the etiologies of chronic liver diseases [19]. As a supplement of the STARD statements, the LiverFibroSTARD checklist and its glossary are new tools specifically designed for the evaluation of diagnostic studies about non-invasive liver fibrosis tests. Liver-FibroSTARD statements should allow improving design and reporting in this field and could be the beginning of an iterative process by which reporting standards will be continuously improved.

Author contributions: All the authors have accepted responsibility for the entire content of this submitted manuscript and approved submission.

Financial support: None declared.

Employment or leadership: None declared.

Honorarium: None declared.

Competing interests: The funding organization(s) played no role in the study design; in the collection, analysis, and interpretation of data; in the writing of the report; or in the decision to submit the report for publication.

\section{References}

1. Chou R, Wasson N. Blood tests to diagnose fibrosis or cirrhosis in patients with chronic hepatitis C virus Infection. A systematic review. Ann Intern Med 2013;158:807-20.

2. Bota S, Herkner H, Sporea I, Salzl P, Sirli R, Neghina AM, et al. Meta-analysis: ARFI elastography versus transient elastography for the evaluation of liver fibrosis. Liver Int 2013;33:1138-47.

3. Sebastiani G. Serum biomarkers for the non-invasive diagnosis of liver fibrosis: the importance of being validated. Clin Chem Lab Med 2012;50:595-7.

4. Moher D, Altman D, Schulz K, Simera I, Wager E. Guidelines for reporting health research: a user's manual. Br Med J Books. Hoboken, NJ: John Wiley \& Sons, 2014:344.

5. Bossuyt PM, Reitsma JB, Bruns DE, Gatsonis CA, Glasziou PP, Irwig LM, et al. Towards complete and accurate reporting of studies of diagnostic accuracy: the STARD initiative. Clin Chem Lab Med 2003;41:68-73.

6. Ochodo EA, Bossuyt PM. Reporting the accuracy of diagnostic tests: the STARD initiative 10 years on. Clin Chem 2013;59:917-9.
7. McShane LM, Altman DG, Sauerbrei W, Taube SE, Gion M, Clark GM. Reporting recommendations for tumor marker prognostic studies (REMARK). J Natl Cancer Inst 2005;97:1180-4.

8. Noel-Storr AH, McCleery JM, Richard E, Ritchie CW, Flicker L, Cullum SJ, et al. Reporting standards for studies of diagnostic test accuracy in dementia: the STARDdem Initiative. Neurology 2014;83:364-73.

9. Moore CM, Kasivisvanathan V, Eggener S, Emberton M, Fütterer JJ, Gill IS, et al. Standards of reporting for MRI-targeted biopsy studies (START) of the prostate: recommendations from an international working group. Eur Urol 2013;64:544-52.

10. Gardner IA, Nielsen SS, Whittington RJ, Collins MT, Bakker D, Harris B, et al. Consensus-based reporting standards for diagnostic test accuracy studies for paratuberculosis in ruminants. Prev Vet Med 2011;101:18-34.

11. Benchimol El, Manuel DG, To T, Griffiths AM, Rabeneck L, Guttmanna A. Development and use of reporting guidelines for assessing the quality of validation studies of health administrative data. J Clin Epidemiol 2011;64:821-9.

12. Bedossa P, Carrat F. Liver biopsy: the best, not the gold standard. J Hepatol 2009;50:1-3.

13. Poynard T, Halfon P, Castera L, Munteanu M, Imbert-Bismut F, Ratziu V, et al. Standardization of ROC curve areas for diagnostic evaluation of liver fibrosis markers based on prevalences of fibrosis stages. Clin Chem 2007;53:1615-22.

14. Lambert J, Halfon P, Penaranda G, Bedossa P, Cacoub P, Carrat F. How to measure the diagnostic accuracy of non-invasive liver fibrosis indices: the area under the ROC curve revisited. Clin Chem 2008;54:1372-8.

15. Boursier J, de Ledinghen V, Poynard T, Guéchot J, Carrat F, Leroy V, et al. An extension of STARD statements for reporting diagnostic accuracy studies on liver fibrosis tests: the Liver-FibroSTARD standards. J Hepatol 2015;62807-15.

16. Association Française pour l'étude du Foie. The FibroSTARD checklist. Available from: http://www.afef.asso.fr/rc/org/afef/ nws/News/2014/20140623-185907-027/src/nws_fullText/fr/ Table\%202\%20Fibro-STARD\%20checklist\%20by\%20AFEF.pdf. Accessed on 19 March 2015.

17. Association Française pour l'étude du Foie. The FibroSTARD glossary. Available from: http://www.afef.asso.fr/rc/org/afef/ nws/News/2014/20140623-185907-027/src/nws_fullText/ fr/FibroSTARD\%20glossary\%20by\%20AFEF.pdf. Accessed on 19 March 2015.

18. Torok N, Dranoff JA, Schuppan D, Friedman SL. Strategies and endpoints of antifibrotic drug trials. Hepatology [Epub ahead of print 27 Jan 2015]. doi: 10.1002/hep.27720.

19. Crossan C, Tsochatzis EA, Longworth L, Gurusamy K, Davidson B, Rodríguez-Perálvarez $M$, et al. Cost-effectiveness of non-invasive methods for assessment and monitoring of liver fibrosis and cirrhosis in patients with chronic liver disease: systematic review and economic evaluation. Health Technol Assess 2015;19:1-410.

asssociation Française pour l'Étude du Foie (French Association for the Study of the Liver), Paris, France

Corresponding author: Docteur Jérôme Guéchot, Hôpital Saint Antoine, 184 Rue du Faubourg Saint Antoine, 75571 Paris Cedex 12, France, E-mail: jerome.guechot@sat.aphp.fr; and Department of Laboratory Medicine, Saint-Antoine Hospital, AP-HP, Paris, France 
Jérôme Boursier, Sandrine Bertrais and Paul Calès: Hepatology Department, University Hospital \& LUNAM University, Angers, France Victor de Ledinghen: Centre d'Investigation de la Fibrose Hépatique, Hôpital Haut-Lévêque, Pessac \& INSERM U1053, Université de Bordeaux, Bordeaux, France

Thierry Poynard: Hepatology Department, Groupe Hospitalier PitièSalpêtrière, AP-HP \& University Pierre et Marie Curie, Paris, France Fabrice Carrat: Sorbonne Universités, University Pierre et Marie Curie, UMR S 1136, Institut Pierre Louis d'Epidémiologie et de Santé Publique \& Public Health Unit, Saint-Antoine Hospital, AP-HP, Paris, France Vincent Leroy: Hepato-gastroenterology Clinic, University Hospital, INSERM U823, Grenoble-Alpes University, Grenoble, France Grace Lai-Hung Wong: Institute of Digestive Disease, Department of Medicine and Therapeutics \& State Key Laboratory of Digestive Disease, The Chinese University of Hong Kong, Hong Kong Mireen Friedrich-Rust: Department of Internal Medicine 1, J.W. Goethe-University Hospital, Frankfurt am Main, Germany
Mirella Fraquelli: Gastroenterology and Endoscopy Unit, Fondazione IRCCS Cà Granda Ospedale Maggiore Policlinico, Department of Pathophysiology and Transplantation, Università degli Studi di Milano, Milano, Italy

Mario Plebani: Department of Laboratory Medicine, UniversityHospital, Padua, Italy

Giada Sebastiani: Division of Gastroenterology, Royal Victoria Hospital, McGill University Health Centre, Montreal, QC, Canada Robert Myers: Liver Unit, Division of Gastroenterology and Hepatology, University of Calgary, Calgary, Alberta, Canada Paul Angulo: Division of Digestive Diseases and Nutrition, University of Kentucky, Medical Center, Lexington, USA Dominique Wendum: Department of Pathology, Saint Antoine Hospital, AP-HP \& Sorbonne Universités, University Pierre et Marie Curie, Paris, France

Ivan Bricault: Department of Radiology, University Hospital Michallon, Grenoble-Alpes University, Grenoble, France 